(c) American Dairy Science Association, 2006.

\title{
Immunomodulatory Effects of Polysaccharides Produced by Lactobacillus delbrueckii ssp. bulgaricus OLL1073R-1
}

\author{
S. Makino, ${ }^{*}$ S. Ikegami, ${ }^{*}$ H. Kano, ${ }^{*}$ T. Sashihara, ${ }^{*}$ H. Sugano, ${ }^{*}$ H. Horiuchi,† T. Saito,‡ and M. Oda* \\ *Food Science Institute, and \\ †Research and Development Center, Meiji Dairies Corp., 540 Naruda, Odawara, Kanagawa 250-0862, Japan \\ łLaboratory of Animal Products Chemistry, Graduate School of Agricultural Science, Tohoku University, Japan
}

\section{ABSTRACT}

The extracellular polysaccharides (EPS) produced by lactic acid bacteria (LAB) are associated with the rheology, texture, and mouthfeel of fermented milk products, including yogurt. This study investigated the immunomodulatory effects of EPS purified from the culture supernatant of Lactobacillus delbrueckii ssp. bulgaricus (L. bulgaricus) OLL1073R-1. The crude EPS were prepared from the culture supernatant of $L$. bulgaricus OLL1073R-1 by standard chromatographic methods, and were fractionated into neutral EPS and acidic EPS (APS). Acidic EPS were further fractionated into high molecular weight APS (H-APS) and low molecular weight APS (L-APS). High molecular weight APS were shown to be phosphopolysaccharides containing D-glucose, D-galactose, and phosphorus. Stimulation of mouse splenocytes by H-APS significantly increased interferon- $\gamma$ production, and, moreover, orally administered H-APS augmented natural killer cell activity. Oral administration of yogurt fermented with $L$. bulgaricus OLL1073R-1 and Streptococcus thermophilus OLS3059 to mice showed a similar level of immunomodulation as H-APS. However, these effects were not detected following administration of yogurt fermented with the starter combination of L. bulgaricus OLL1256 and $S$. thermophilus OLS3295. We conclude from these findings that yogurt fermented with $L$. bulgaricus OLL1073R-1, containing immunostimulative EPS, would have an immunomodulatory effect on the human body.

Key words: extracellular polysaccharide, immunomodulatory effect, Lactobacillus delbrueckii ssp. bulgaricus, yogurt

\section{INTRODUCTION}

Lactic acid bacteria ( $\mathbf{L A B})$ have been widely used the production of fermented dairy foods for many years. It

Received November 23, 2005.

Accepted February 20, 2006.

${ }^{1}$ Corresponding author: seiya_makino@meiji-milk.com has recently been reported that some LAB and their metabolites have immunological effects and can modulate the immune system following oral administration (Gill, 1998; Cross et al., 2001). Several LAB strains have been shown to enhance cell-mediated immune responses, including T-lymphocyte proliferative ability, mononuclear cell phagocytic capacity, and natural killer (NK) cell tumoricidal activity (Cross et al., 2001). Extracellular polysaccharides (EPS), which are metabolites of some LAB strains, were also reported to exhibit antitumor activity (Oda et al., 1983), macrophage activation (Kitazawa et al., 1991), mitogenic activity (Kitazawa et al., 1993), and induction of cytokines (Kitazawa et al., 1996). However, most of these studies were performed in vitro and little information is available from in vivo experiments involving oral administration (Ruas-Madiedo et al., 2002).

Lactobacillus delbrueckii ssp. bulgaricus (L. bulgaricus) OLL1073R-1 has been shown to exert host-mediated antitumor activity in mice (Ebina et al., 1995). In vitro experiments have revealed the mitogenic activity of EPS produced by this strain (Kitazawa et al., 1998) through macrophage activation (Nishimura-Uemura et al., 2003). The present study was conducted to examine whether EPS from L. bulgaricus OLL1073R-1 stimulate cell-mediated immune responses through induction of IFN- $\gamma$ production in mouse splenocytes. Furthermore, we examined whether oral administration of EPS or yogurt fermented with L. bulgaricus OLL1073R-1 would increase IFN- $\gamma$ production and augment NK cell activity in mouse splenocytes.

\section{MATERIALS AND METHODS}

\section{Microorganisms and Media}

Four LAB strains, L. bulgaricus OLL1073R-1, L. bulgaricus OLL1256, Streptococcus thermophilus OLS3059, and S. thermophilus OLS3295, were used in this study. These strains were originally isolated from Bulgarian traditional yogurt. The $L$. bulgaricus strains were cultured on medium containing $10 \%$ (wt/vol) skim milk powder or whey powder and $0.5 \%$ (wt/vol) yeast extract (Becton Dickinson, Sparks, MD), hereafter re- 
ferred to as skim milk medium and whey medium, respectively. The whey powder had been hydrolyzed with protease A (Amano2, EC 3.4.24.39; Amano Enzyme, Nagoya, Japan) for $7 \mathrm{~h}$ at $55^{\circ} \mathrm{C}$ before use. Streptococcus thermophilus strains were cultured on skim milk medium.

\section{Mice}

Pathogen-free C3H/HeJ and BALB/c male mice were purchased from SLC Inc. (Hamamatsu, Shizuoka, Japan), and used between 8 and $15 \mathrm{wk}$ of age; C3H/HeJ mice are resistant to LPS. All experiments were performed in accordance with the guidelines of the ethical committee for animal experiments of the Meiji Dairies Corporation, Japan.

\section{Preparation of Crude EPS Produced by L. bulgaricus OLL1073R-1}

Lactobacillus bulgaricus OLL1073R-1 was cultured at $37^{\circ} \mathrm{C}$ for $24 \mathrm{~h}$ on whey medium. After cultivation, bacterial cells and precipitates were removed by centrifugation $\left(16,000 \times g, 20 \mathrm{~min}, 4^{\circ} \mathrm{C}\right)$. Crude EPS were precipitated from the supernatant by the addition of 1.5 volumes of cold $\mathrm{EtOH}$, and collected by centrifugation $\left(16,000 \times g, 20 \mathrm{~min}, 4^{\circ} \mathrm{C}\right)$. The crude EPS were dissolved in distilled water, and insoluble material was removed by centrifugation $\left(16,000 \times g, 20 \mathrm{~min}, 4^{\circ} \mathrm{C}\right)$. The crude EPS were purified by additional precipitation with 1.5 volumes of cold EtOH. The crude EPS were treated with $10 \%$ (wt/vol) TCA at $4^{\circ} \mathrm{C}$ for $16 \mathrm{~h}$, and the denatured proteins were removed by centrifugation $(16,000 \times g$, $20 \mathrm{~min}, 4^{\circ} \mathrm{C}$ ). The partially purified EPS were obtained by dialysis of the supernatant containing the crude EPS against distilled water at $4^{\circ} \mathrm{C}$ for $4 \mathrm{~d}$, followed by lyophilization.

\section{EPS Fractionation}

The partially purified EPS were fractionated into neutral EPS (NPS) and acidic EPS (APS) by anionexchange chromatography with a DEAE-sepharose column $(5 \times 25 \mathrm{~cm}$; Amersham Biosciences, Piscataway, $\mathrm{NJ}$ ). The linear gradient of elution was from 0 to 0.4 $M \mathrm{NaCl}$ in $20 \mathrm{~m} M$ Tris- $\mathrm{HCl}$ buffer (pH 8.6). The eluate was photometrically monitored for proteins at $280 \mathrm{~nm}$ and for neutral sugars at $490 \mathrm{~nm}$ by the phenol- $\mathrm{H}_{2} \mathrm{SO}_{4}$ reaction (Dubois et al., 1956). The eluted fractions (fraction 44 to 55) of APS were further fractionated into high molecular weight APS (H-APS) and low molecular weight APS (L-APS) by gel filtration chromatography with a Sephacryl S- $400 H R$ column $(2.5 \times 92 \mathrm{~cm}$; Amersham Biosciences) in $50 \mathrm{~m} M$ phosphate buffer ( $\mathrm{pH}$ 6.0) containing $150 \mathrm{~m} M \mathrm{NaCl}$. Neutral EPS, H-APS, and LAPS were lyophilized after dialysis against distilled water at $4^{\circ} \mathrm{C}$ for $4 \mathrm{~d}$.

\section{Estimation of the APS Molecular Weight}

Crude EPS were dissolved in $0.05 M$ Tris-HCl buffer (pH 8.0) containing $1 \mathrm{mM} \mathrm{MgCl} 2$, and treated with 2 $\mu \mathrm{g} / \mathrm{mL}$ DNase (EC 3.1.21.1; Sigma, St. Louis, MO) and $2 \mu \mathrm{g} / \mathrm{mL}$ RNase (type I-AS, EC 3.1.27.5; Sigma) at $37^{\circ} \mathrm{C}$ for $6 \mathrm{~h}$. The proteins in crude EPS were digested with $0.2 \mathrm{mg} / \mathrm{mL}$ of proteinase K (EC 3.4.21.64; Sigma) for $16 \mathrm{~h}$ at $37^{\circ} \mathrm{C}$. The reaction was stopped by heating at $90^{\circ} \mathrm{C}$ for $10 \mathrm{~min}$, and the enzyme-treated crude EPS were precipitated with cold EtOH as previously described. Acidic EPS were purified from the enzymetreated crude EPS by anion-exchange chromatography as previously described.

The molecular weight of APS was estimated by HPLC with an Asahipak GS-710 7G column $(7.6 \times 500 \mathrm{~mm}$; Shodex, Tokyo, Japan), and a refractive index detector (2414 Refractive Index Detector; Waters, Milford, MA). Elution was conducted isocratically with distilled water containing $0.2 \mathrm{M} \mathrm{NaCl}$ at a flow rate of $0.5 \mathrm{~mL} / \mathrm{min}$ at $30^{\circ} \mathrm{C}$. The eluting volume from the column was calibrated with a pullulan kit containing P-1600, P-800, P400, P-200, P-100, P-50, P-20, P-10, and P-5 standards (Shodex).

\section{Chemical Composition Analysis of EPS}

The EPS sample was hydrolyzed in $1 \mathrm{~N} \mathrm{H}_{2} \mathrm{SO}_{4}$ at $100^{\circ} \mathrm{C}$ for $4 \mathrm{~h}$. The hydrolysate was neutralized with $\mathrm{BaCO}_{3}$, and the precipitate was removed by filtration using a $0.45-\mu \mathrm{m}$ filter unit (Millipore, Molsheim, France). The filtrate was eluted by HPLC with a Shodex Sugar SP0810 column $(8 \times 300 \mathrm{~mm}$; Shodex $)$, and monosaccharides were detected using a refractive index detector (YRD-880; Shimamura, Tokyo, Japan). Elution was conducted isocratically with distilled water at a flow rate of $0.5 \mathrm{~mL} / \mathrm{min}$ at $70^{\circ} \mathrm{C}$. The molar ratio of monosaccharides in the sample was estimated using a standard curve.

The phosphorus content of the EPS was determined by the Bartlett method (Bartlett, 1959) using $\mathrm{KH}_{2} \mathrm{PO}_{4}$ as a standard. The EPS was purified as a high molecular weight polysaccharide by HPLC with an Asahipak GS$71020 \mathrm{G}$ column $(20 \times 500 \mathrm{~mm}$; Shodex $)$ and a refractive index detector (2414 Refractive Index Detector; Waters). Elution was conducted isocratically with distilled water containing $0.2 \mathrm{M} \mathrm{NaCl}$ at a flow rate of $1.0 \mathrm{~mL} /$ min at $30^{\circ} \mathrm{C}$. The total carbohydrate concentration was determined by the phenol- $\mathrm{H}_{2} \mathrm{SO}_{4}$ reaction using glucose as a standard. 


\section{Cytokine Assay}

Whole mouse splenocytes prepared aseptically were dispersed into RPMI 1640 (Gibco, Grand Island, NY) supplemented with $100 \mathrm{U} / \mathrm{mL}$ penicillin G (Gibco), 100 $\mu \mathrm{g} / \mathrm{mL}$ streptomycin (Gibco), $2 \mathrm{~m} M_{\text {L-glutamine (Gibco), }}$ $1 \mathrm{~m} M$ sodium pyruvate (Gibco), $0.1 \mathrm{~m} M$ minimal essential medium with nonessential amino acids (Gibco), and 10\% (vol/vol) fetal calf serum (RPMI 1640 medium). The cells were washed with the same cold medium and were suspended at a concentration of $5 \times 10^{6}$ cells $/ \mathrm{mL}$. The single-cell suspension was dispensed into 96-well tissue culture plates (3596 Corning; Corning, NY) at $5 \times$ $10^{5}$ cells/well in RPMI 1640 medium. Each well received EPS at 20,100 , or $500 \mu \mathrm{g} / \mathrm{mL}$, and was incubated for $72 \mathrm{~h}$ at $37^{\circ} \mathrm{C}$ in a humidified $5 \% \mathrm{CO}_{2}$-air atmosphere. Splenocytes from mice administered H-APS or yogurt were stimulated with concanavalin A (ConA; Sigma) at $1 \mu \mathrm{g} / \mathrm{mL}$, and were incubated for $72 \mathrm{~h}$ at $37^{\circ} \mathrm{C}$ in a humidified 5\% $\mathrm{CO}_{2}$-air atmosphere. After incubation, the plates were centrifuged $\left(120 \times \mathrm{g}, 5 \mathrm{~min}, 4^{\circ} \mathrm{C}\right)$, and the culture supernatants were collected. The concentration of IFN- $\gamma$ and IL-4 in each supernatant was determined by ELISA using the Mouse IFN- $\gamma$ ELISA Kit (Endogen, Rockford, IL) and Opt EIA Set mouse IL-4 (Becton Dickinson, San Diego, CA) according to the manufacturer's protocols.

\section{Oral Administration of H-APS}

After acclimation for $1 \mathrm{wk}, 30 \mathrm{BALB} / \mathrm{c}$ mice (8 wk old) were divided into 3 groups with 10 animals in each. The first group received a 3 -wk oral administration of $5 \mathrm{mg} / \mathrm{kg}$ per d of H-APS dissolved in distilled water; the second group received $30 \mathrm{mg} / \mathrm{kg}$ per $\mathrm{d}$ of H-APS administered in the same way; the third (control) group received $0.5 \mathrm{~mL} / \mathrm{d}$ of distilled water via gastric intubation with an animal-feeding needle. The H-APS was purified from the crude EPS of $L$. bulgaricus OLL1073R-1 by anion-exchange chromatography and gel permeation chromatography (as described above). Three weeks after the first administration, the mice were killed, and the splenocytes were isolated.

\section{NK Cell Activity}

The NK cell activity of mouse splenocytes was assessed using flow cytometry (Johann et al., 1995); YAC1 cells were used as the target cells, and $0.5 \times 10^{6}$ YAC-1 cell $\mathrm{s} / \mathrm{mL}$ were labeled with $2.5 \mu \mathrm{g} / \mathrm{mL}$ of $3,3^{\prime}-$ dioctadecyloxacarbocyanine perchlorate (Sigma) by overnight incubation at $37^{\circ} \mathrm{C}$. The cells were washed 3 times with RPMI 1640 medium, and resuspended at a concentration of $2.5 \times 10^{5}$ cells $/ \mathrm{mL}$. Mouse spleen lymphocyte effector cells $\left(10^{6} /\right.$ well) were added to target cells at $2.5 \times 10^{4}$ cells/well (40:1 ratio) in a total volume of $200 \mu \mathrm{L} /$ well in a 96 -well, round-bottomed plate (3799 Corning). Samples were centrifuged $(30 \times g, 1 \mathrm{~min})$, and incubated for $4 \mathrm{~h}$ at $37^{\circ} \mathrm{C}$ in a humidified $5 \% \mathrm{CO}_{2^{-}}$ air atmosphere. Fifteen minutes before the end of the incubation, $20 \mu \mathrm{L}$ of propidium iodide $(0.5 \mathrm{mg} / \mathrm{mL}$ in PBS; Sigma) was added to each well to label the dead cells. The level of target cell lysis was determined using a FACSCalibur flow cytometer (Becton Dickinson), and the NK cell activity was expressed as the percentage of effector cell-specific lysis.

\section{Oral Administration of Yogurt}

After acclimation for $1 \mathrm{wk}, 32 \mathrm{BALB} / \mathrm{c}$ mice (11 wk old) were divided into 4 groups of 8 mice. The first and second groups received a 4 -wk oral administration of $200 \mathrm{mg} / \mathrm{d}$ of 2 types of lyophilized yogurt, respectively. The third group received unfermented milk dissolved in distilled water administered in the same way, and the fourth (control) group received $1.0 \mathrm{~mL}$ of distilled water/d via gastric intubation with an animal-feeding needle. Four weeks after the first administration, the mice were killed, and the splenocytes were isolated.

Yogurt was fermented by inoculation of pasteurized milk containing $3 \%(\mathrm{wt} / \mathrm{wt})$ sucrose with $L$. bulgaricus OLL1073R-1 and S. thermophilus OLS3059 (or L. bulgaricus OLL1256 and S. thermophilus OLS3295). Each $\mathrm{LAB}$ starter culture was grown at $37^{\circ} \mathrm{C}$ for 18 to $24 \mathrm{~h}$ and inoculated at $1 \%(\mathrm{wt} / \mathrm{wt})$ concentration. Fermentation was performed at $43^{\circ} \mathrm{C}$ until culture acidity reached $0.70 \%$. After fermentation, the yogurt was cooled overnight and lyophilized.

\section{Purification of EPS from Yogurt}

After centrifugation $\left(16,000 \times \mathrm{g}, 20 \mathrm{~min}, 4^{\circ} \mathrm{C}\right)$ of the yogurt to remove bacterial cells and precipitates, partially purified EPS were obtained using the methods previously described. Crude EPS were obtained after EtOH precipitation and DNase, RNase, and proteinase $\mathrm{K}$ treatment to digest nuclear acids and proteins. Finally, EPS were fractionated by HPLC with an Asahipak GS-710 20G column $(20 \times 500 \mathrm{~mm}$; Shodex $)$, and partially purified EPS were obtained following dialysis against distilled water at $4^{\circ} \mathrm{C}$ for $4 \mathrm{~d}$, and lyophilization.

\section{Statistical Analyses}

The experimental data were expressed as means and their standard deviations (SD). The SD differences were evaluated by the Student's $t$-test and ANOVA employing Dunnett's posthoc test for the concentration of cytokines and NK cell activity, using the StatView 5.0 


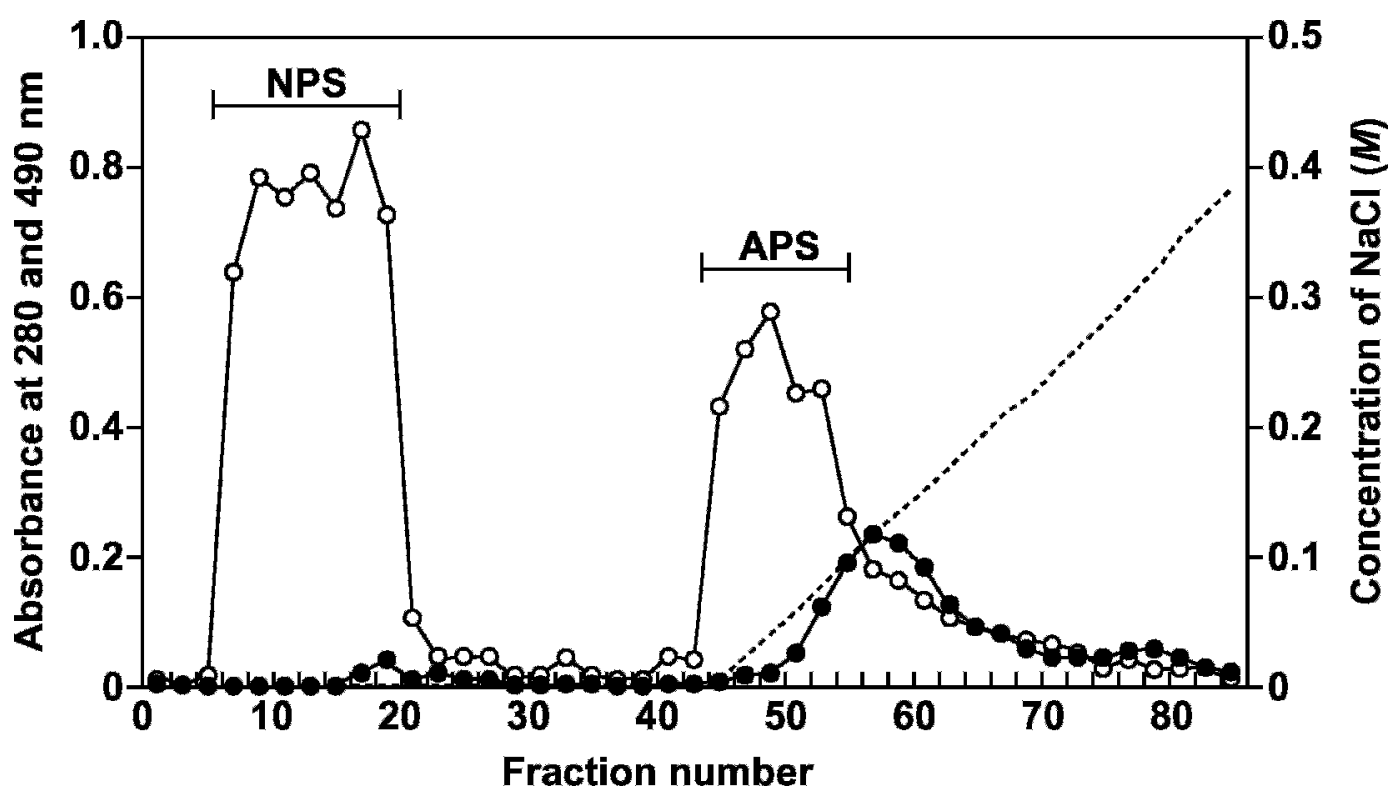

Figure 1. Fractionation of extracellular polysaccharides (EPS) produced by Lactobacillus bulgaricus OLL1073R-1 by anion-exchange chromatography. The eluate (approximately $7.8 \mathrm{~mL} /$ fraction) was monitored for proteins at $280 \mathrm{~nm}(\bullet)$ and for neutral sugars at $490 \mathrm{~nm}$ (O) by the phenol- $\mathrm{H}_{2} \mathrm{SO}_{4}$ method. The dashed line indicates the concentration of NaCl; APS = acidic EPS; NPS = neutral EPS.

program (Abacus Concept Inc., Berkeley, CA). Differences were considered statistically significant at $P<$ 0.05 .

\section{RESULTS}

\section{Purification and Characterization of EPS from L. bulgaricus OLL1073R-1 Culture}

Extracellular polysaccharides prepared from the culture supernatant of L. bulgaricus OLL1073R-1 were fractionated into NPS (fractions 6 to 20) and APS (fractions 44 to 55) by anion-exchange chromatography (Figure 1). Neutral EPS were eluted as high molecular weight polysaccharides, whereas APS contained 2 components (Figure 2), which were fractionated into H-APS (fractions 29 to 37) and L-APS (fractions 47 to 61) by gel filtration chromatography. The sugar compositions of NPS and H-APS were analyzed by HPLC (Table 1). Neutral EPS contained glucose (Glc), galactose (Gal), mannose (Man), and xylose (Xyl) at a ratio of 1:1.31:0.01:0.21. High molecular weight APS contained Glc and Gal at a ratio of 1:1.25. Furthermore, H-APS were shown to be phosphopolysaccharides containing $0.01 \%$ (wt/wt) phosphorus, with a molecular weight estimated at $2.9 \times 10^{6} \mathrm{Da}$ by HPLC (data not shown). Low molecular weight APS were composed solely of Man. We detected similar amounts of purified L-APS from whey medium that had not undergone fermentation by LAB (data not shown). We therefore concluded that L-
APS were derived mainly from the medium, and so we chose not to consider them further in this paper.

\section{Induction of IFN- $\gamma$ Production by Purified NPS and H-APS}

To examine the immunostimulatory abilities of NPS and H-APS, we first investigated their effects on in vitro IFN- $\gamma$ production in $\mathrm{C} 3 \mathrm{H} / \mathrm{HeJ}$ mouse spleen cells. The culture supernatant of mouse splenocytes incubated at $37^{\circ} \mathrm{C}$ for $72 \mathrm{~h}$ with 20 to $500 \mu \mathrm{g} / \mathrm{mL}$ of H-APS showed a significant increase in IFN- $\gamma$ production (Figure 3 ). No stimulatory effects on IFN- $\gamma$ production were induced in mouse splenocytes incubated with NPS.

\section{Effect of H-APS Oral Administration on NK Cell Activity and Cytokine Production}

To investigate whether the oral administration of $\mathrm{H}$ APS could also stimulate the immune system in vivo, we measured the NK cell activity and level of cytokine production in mouse splenocytes. BALB/c mice received a 3 -wk oral administration of 5 or $30 \mathrm{mg} / \mathrm{kg}$ of H-APS per d dissolved in distilled water. A dose-dependent increase in NK cell activity was detected in the splenocytes of the mice administered H-APS at an effector:target cell ratio of 40:1. The highest activity $(P<0.05)$ compared with the control was detected in mice administered $30 \mathrm{mg} / \mathrm{kg}$ per d (Figure 4). In addition, splenocytes from H-APS treated mice ( 5 or $30 \mathrm{mg} / \mathrm{kg}$ per d) 


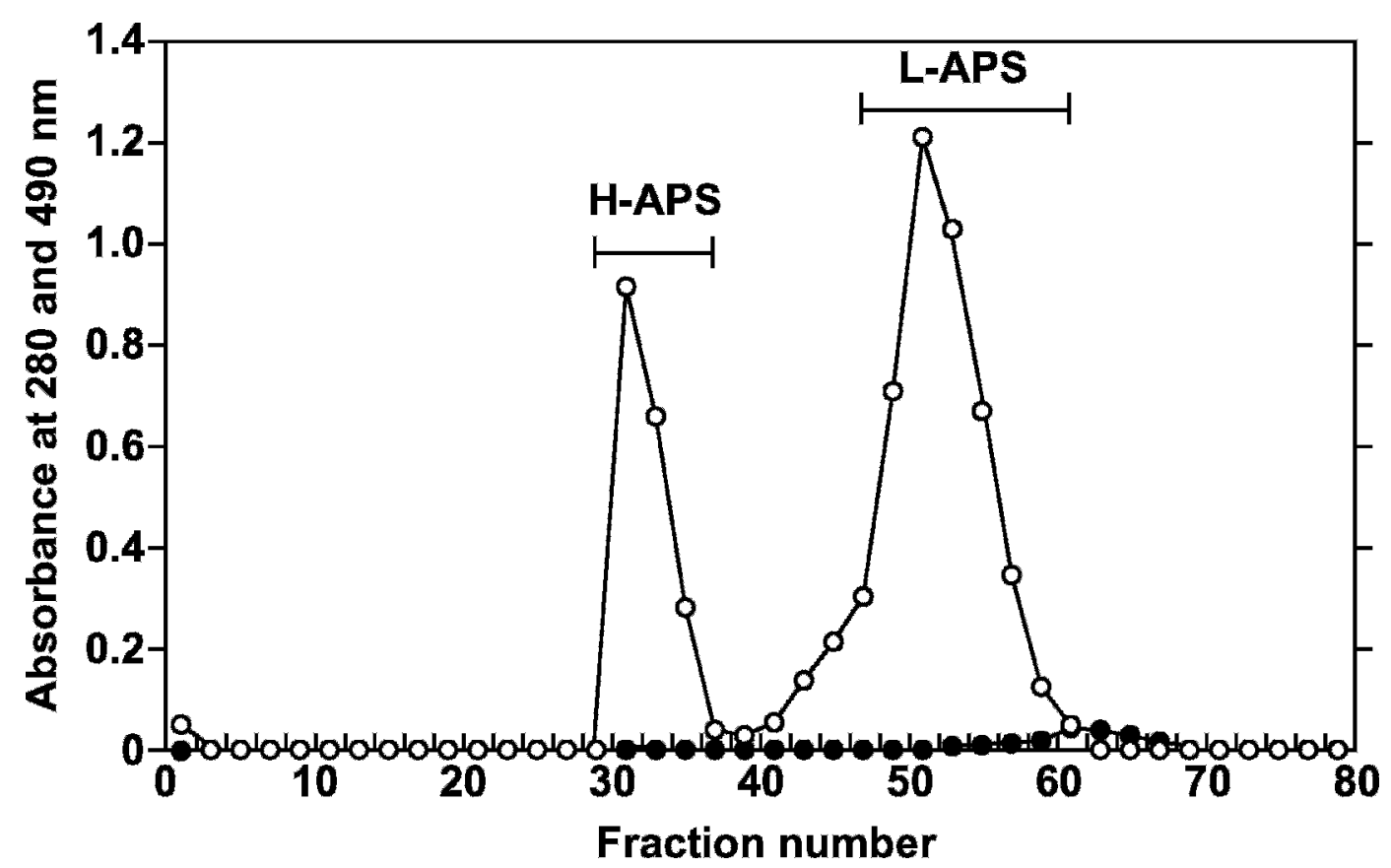

Figure 2. Elution profile of acidic extracellular polysaccharides (APS) by gel filtration chromatography. The eluate (approximately 7.8

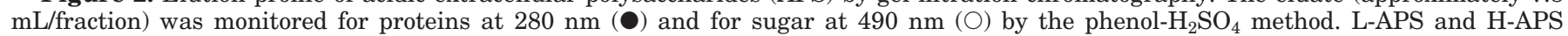
indicated low and high molecular weight APS, respectively.

produced slightly more IFN- $\gamma$ and slightly less IL-4 than those of control mice following stimulation with ConA. However, this difference was not significant.

\section{Effect of Oral Administration of Yogurt Fermented with L. bulgaricus OLL1073R-1 on NK Cell Activity and Cytokine Production}

We next determined whether yogurt fermented with L. bulgaricus OLL1073R-1 had a similar in vivo immunomodulatory effect as H-APS. Thirty-two mice were divided into 4 groups: the first group received "1073R1 yogurt" fermented with $L$. bulgaricus OLL1073R-1 and $S$. thermophilus OLS3059; the second group received "control yogurt" fermented with $L$. bulgaricus OLL1256 and S. thermophilus OLS3295; the third group received unfermented milk; and the fourth group received distilled water. Cell counts of $L$. bulgaricus and $S$. thermophilus in the 2 yogurt preparations were between $2.2 \times 10^{8}$ and $6.9 \times 10^{8} \mathrm{cfu} / \mathrm{g}$.
Yogurt and unfermented milk were lyophilized and administered to mice at $200 \mathrm{mg} / \mathrm{d}$ for $4 \mathrm{wk}$. Natural killer cell activity in splenocytes from mice administered 1073R-1 yogurt showed a significant increase $(P$ $<0.05$ ) compared with control mice (administered distilled water; Figure 5). Moreover, as shown in Figure 6 , ConA-induced IFN- $\gamma$ production tended to increase in splenocytes from mice administered 1073R-1 yogurt compared with control mice $(P=0.053)$ and those administered unfermented milk $(P=0.053)$. By contrast, IL-4 production by splenocytes tended to decrease in mice administered 1073R-1 yogurt compared with control mice $(P=0.067)$. However, only a slight increase in IFN- $\gamma$ production and a slight decrease in IL-4 production were detected in splenocytes of mice administered control yogurt compared with 1073R-1 yogurt.

Thus, we found that administration of 1073R-1 yogurt was effective not only in augmenting NK cell activity but also in increasing IFN- $\gamma$ production and decreasing IL-4 production by splenocytes.

Table 1. Sugar composition of extracellular polysaccharides from Lactobacillus bulgaricus OLL1073R-1

\begin{tabular}{lllll}
\hline & \multicolumn{4}{c}{ Molar ratio of sugars } \\
\cline { 2 - 5 } Polysaccharide & D-Glucose & D-Galactose & Mannose & Xylose \\
\hline Neutral polysaccharide & 1.00 & 1.31 & 0.01 & 0.21 \\
High molecular weight acidic polysaccharide & 1.00 & 1.25 & ND $^{1}$ & ND \\
\hline
\end{tabular}

${ }^{1} \mathrm{ND}=$ Not detected. 


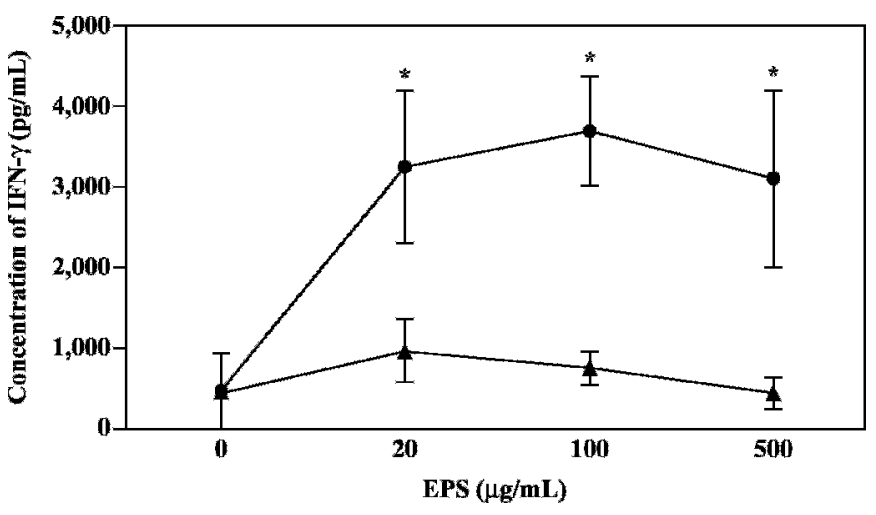

Figure 3. Effect of extracellular polysaccharides (EPS) produced by Lactobacillus bulgaricus OLL1073R-1 on IFN- $\gamma$ production from mouse splenocytes. $\mathrm{C} 3 \mathrm{H} / \mathrm{HeJ}$ mouse splenocytes were incubated with high molecular weight acidic EPS (H-APS, - ) or neutral EPS (NPS, A) for $72 \mathrm{~h}$. Each bar represents the mean value and SD of triplicate samples. An asterisk (*) indicates $P<0.05$ compared with the control using the Dunnett's test.

\section{Induction of IFN- $\gamma$ Production by EPS from Yogurt Fermented with L. bulgaricus OLL1073R-1}

Crude EPS prepared from 1073R-1 yogurt contained approximately $40 \mathrm{mg}$ of EPS per $\mathrm{kg}$ of 1073R-1 yogurt. After further purification, the EPS contained Glc and Gal at a ratio 1:1.65 ratio, as well as $0.02 \%$ (wt/wt) phosphorus (data not shown). We assumed the EPS to be a mixture of NPS and H-APS.

To determine whether the EPS purified from yogurt contained in vitro IFN- $\gamma$ induction activity, we incubated $\mathrm{C} 3 \mathrm{H} / \mathrm{HeJ}$ mouse splenocytes with EPS at $37^{\circ} \mathrm{C}$ for $72 \mathrm{~h}$. A dose-dependent increase in IFN- $\gamma$ activation was observed (Figure 7), with the highest activity $(P<$

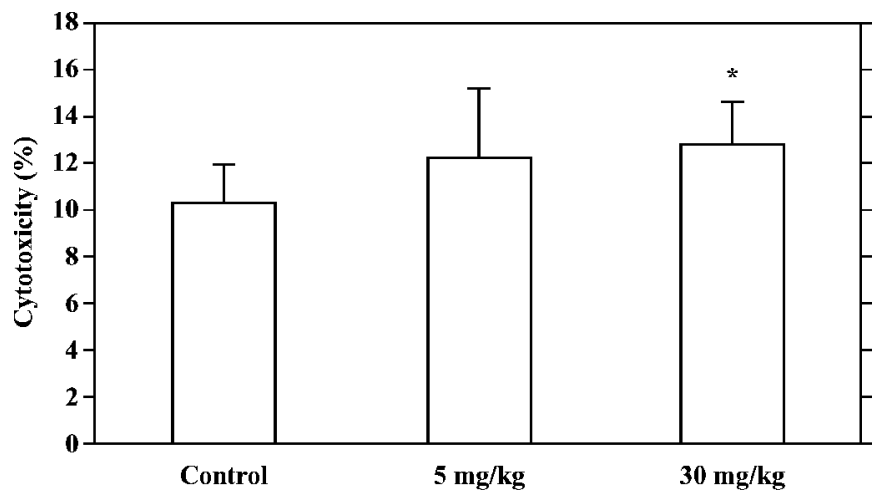

Figure 4. Effect of orally administered high molecular weight acidic extracellular polysaccharides (H-APS) produced by Lactobacillus bulgaricus OLL1073R-1 on natural killer cell activity in mouse splenocytes. Splenocytes from BALB/c mice administered H-APS for 3 wk were examined. Values are means of 10 mice per group. An asterisk (*) indicates $P<0.05$ compared with the control using the Dunnett's test.
0.05) compared with the control detected at concentrations of 100 and $500 \mu \mathrm{g} / \mathrm{mL}$.

\section{DISCUSSION}

In the present study, we demonstrated the presence of phosphorus in H-APS purified from a culture of $L$. bulgaricus OLL1073R-1 using anion-exchange and gel filtration chromatography. In addition, we show that H-APS induced IFN- $\gamma$ production in mouse spleen cells. Kitazawa et al. (1998) also purified a phosphopolysaccharide from the culture of L. bulgaricus OLL1073R-1 using chromatographic methods. The structure of its carbohydrate moiety was similar to that of the H-APS in the present study, but the amount of phosphorus differed $(0.1 \% \mathrm{wt} / \mathrm{wt})$. Furthermore, the phosphopolysaccharide purified by Kitazawa et al. (1998) was composed of a pentasaccharide repeating unit of 2 Glc and $3 \mathrm{Gal}$ with $2 \alpha$ - and $3 \beta$-orientation (Uemura et al., 1998). It therefore appears that H-APS, which contained Glc, Gal, and phosphorus, were almost identical to this phosphopolysaccharide, with minor differences in the molar ratio of the monosaccharide and phosphorus contents. These differences might depend on the culture conditions of L. bulgaricus OLL1073R-1, such as the temperature and medium composition, because our results show that the total EPS (presumably NPS and H-APS) purified from 1073R-1 yogurt contained more phosphorus than the H-APS purified from the culture of $L$. bulgaricus OLL1073R-1, which was cultured on wheybased medium at $37^{\circ} \mathrm{C}$.

Kitazawa et al. (1998) also reported that the phosphopolysaccharide produced by L. bulgaricus OLL1073R1 exerted mitogenic activity in vitro, and that its immunostimulatory effect was decreased by dephosphorylation. Sato et al. (2004) showed that dextran with a chemically introduced phosphate group also exerted mitogenic activity; and phosphorylated dextran activated dendritic cells and increased the level of IFN- $\gamma$ mRNA expression by murine splenocytes in vitro. It is therefore reasonable to assume that the effect of H-APS on IFN$\gamma$ production was due to the presence of phosphorus in H-APS.

In the present study, we demonstrated that splenocytes from mice orally administered with H-APS exhibited a dose-dependent increase in NK cell activity. This is the first report that oral administration of EPS produced by $L$. bulgaricus can modulate the immune system. The precise mechanism responsible for the augmentation of NK cell activity is yet to be identified; however, we assume that the EPS are taken up by Peyer's patches in the intestine and stimulate antigenpresenting cells, such as dendritic cells, through tolllike receptors. This would result in selective enhance- 


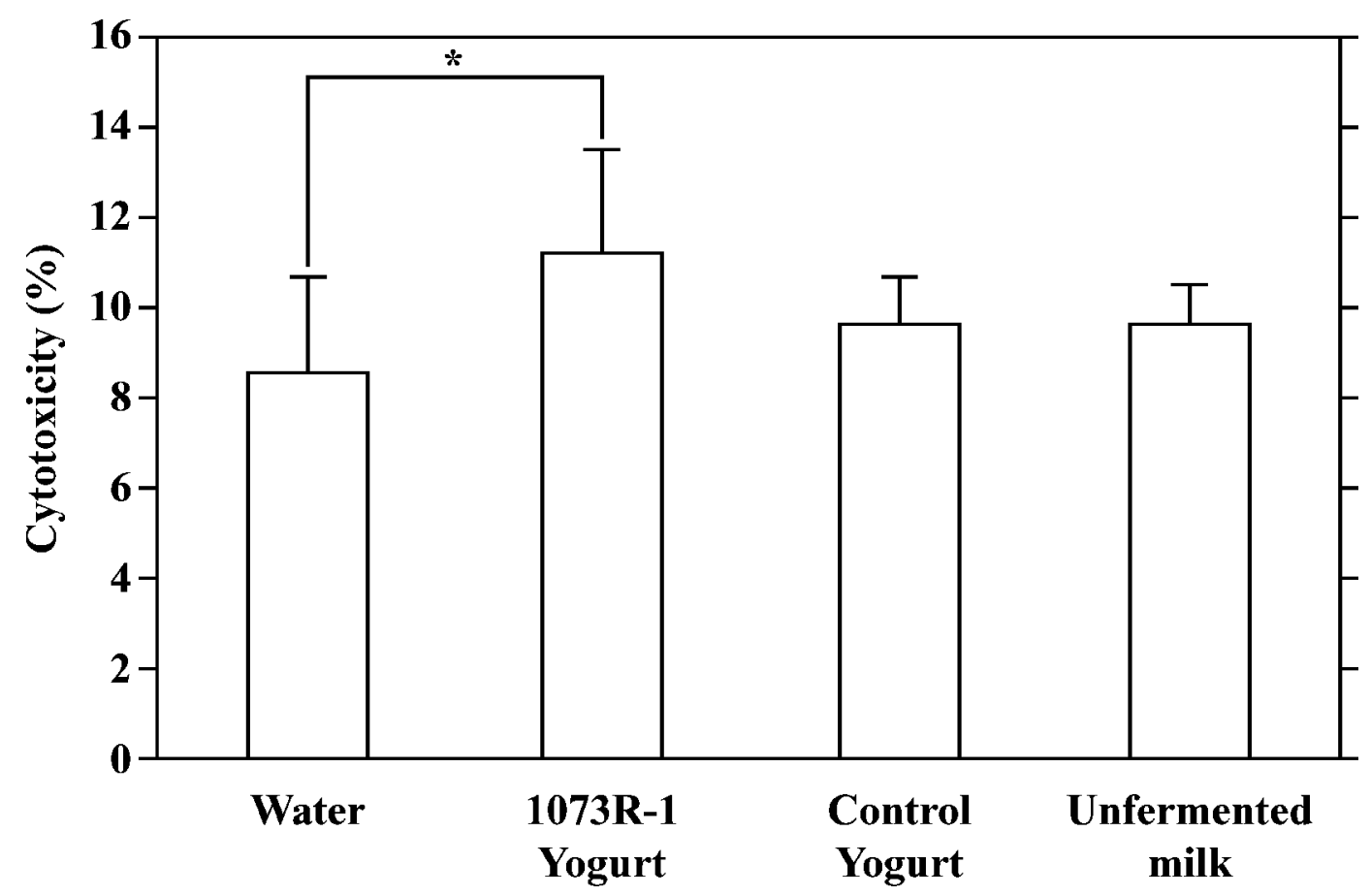

Figure 5. Effect of orally administered yogurt fermented with Lactobacillus bulgaricus OLL1073R-1 on natural killer cell activity in splenocytes of BALB/c mice. Splenocytes from mice administered yogurt fermented with L. bulgaricus OLL1073R-1 and Streptococcus thermophilus OLS3059 (1073R-1 yogurt) for 4 wk were examined. Control yogurt was fermented with L. bulgaricus OLL1256 and S. thermophilus OLS3295. Values are means of 8 mice per group. An asterisk (*) indicates $P<0.05$ compared with the control using the Student's $t$-test.

ment of T-helper 1 (Th1) cell proliferation, and the subsequent production of IL-2 and IFN- $\gamma$, which are cytokines that are vital for cell-mediated immune responses (Mossmann and Coffman, 1989). Interferon- $\gamma$ not only activates NK cells and macrophages but also selectively inhibits the proliferation of Th2 cells, which produce cytokines such as IL- 4 . We therefore examined the production of IFN- $\gamma$ and IL- 4 by splenocytes from mice administered H-APS. Although the splenocytes cells from H-APS-treated mice produced slightly more IFN$\gamma$ and slightly less IL-4 than those of control mice when they were stimulated with ConA, we were unable to observe a significant difference in cytokine levels.

We show that the oral administration of yogurt fermented with L. bulgaricus OLL1073R-1 and S. thermophilus OLS3059 result in almost the same immunomodulatory effects as H-APS administration; namely, the augmentation of NK cell activity, an increase of IFN- $\gamma$ production, and a decrease of IL- 4 production. Consequently, we propose that the EPS produced by $L$. bulgaricus OLL1073R-1 played an important role for the yogurt to exert these immunomodulatory effects. Approximately $40 \mathrm{mg}$ of EPS was purified from $1 \mathrm{~kg}$ of yogurt; therefore, yogurt EPS would be expected to exert immunomodulatory effects at a lesser amount than
H-APS. It is likely that yogurt contains more EPS than was calculated from the partially purified product in the current study, because EPS are known to bond with casein, which would be easily removed by centrifugation.

A possible contributory role of the bacterial cells in the immunomodulatory effects of 1073R-1 yogurt cannot be excluded. A previous study demonstrated that the cells of $L$. bulgaricus OLL1073R-1 exerted hostmediated antitumor activity in mice (Ebina et al., 1995). However, in this study, unfermented milk and yogurt fermented with L. bulgaricus OLL1256 and S. thermophilus OLS3295 were less effective than 1073R-1 yogurt in exerting immunomodulatory effects. Our results and those of others (Gill et al., 2000; Hori et al., 2002) suggest that the immunomodulatory effects depend on the bacterial strains used.

In a human study, the consumption of LAB was shown to enhance cell-mediated immune responses in the elderly (Gill et al., 2001; Sheih et al., 2001). These strains have also demonstrated a protective effect against Escherichia coli O157:H7 infection in mice (Shu and Gill, 2001, 2002). Lactobacillus casei strain Shirota has been reported to augment the NK cell activity of splenocytes in aged mice, and of peripheral blood mono- 

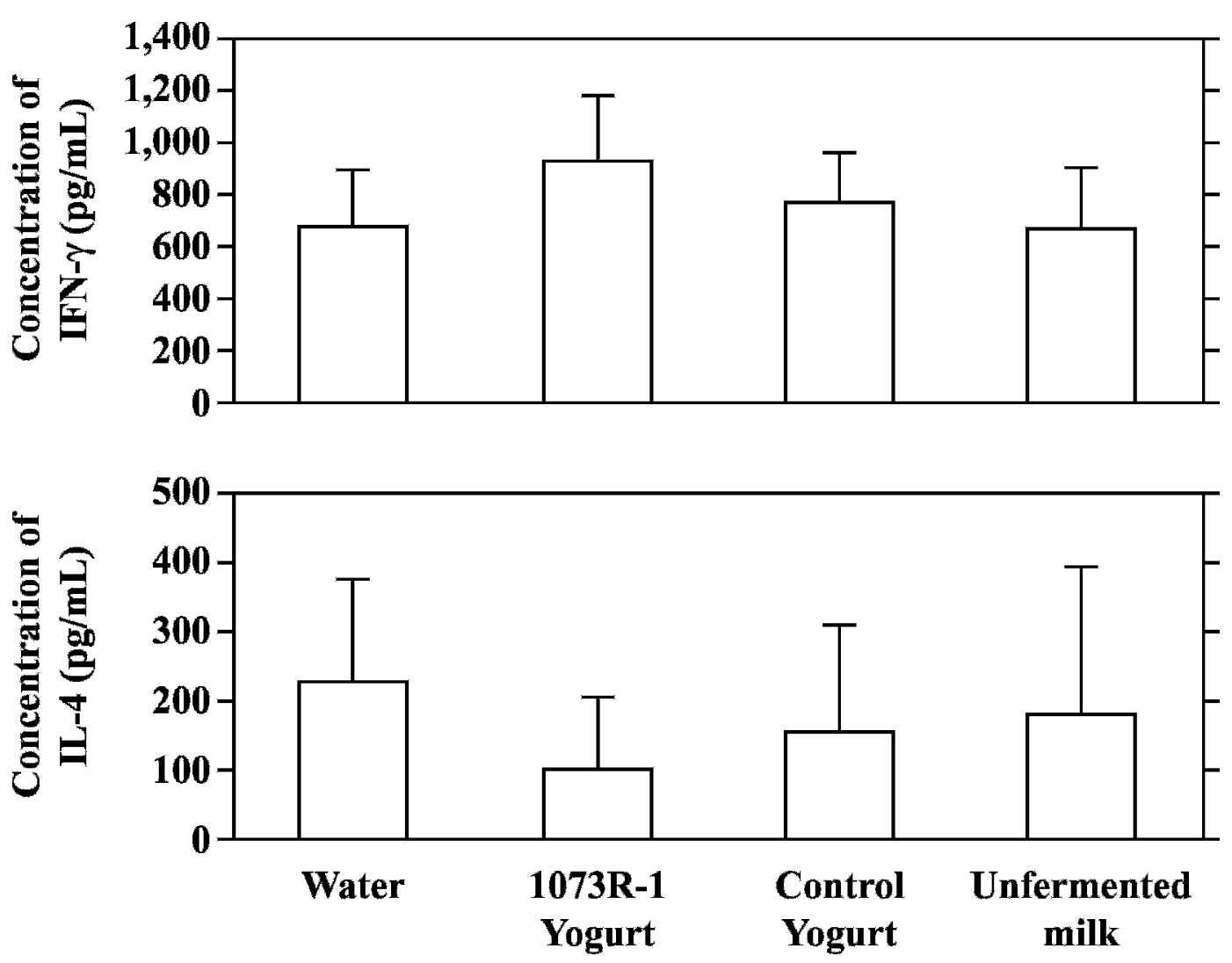

Figure 6. Effect of orally administered yogurt fermented with Lactobacillus bulgaricus OLL1073R-1 on the production of IFN- $\gamma$ and IL4 by BALB/c mouse splenocytes. Splenocytes from mice administered yogurt fermented with L. bulgaricus OLL1073R-1 and Streptococcus thermophilus OLS3059 (1073R-1 yogurt) for 4 wk were examined. Control yogurt was fermented with L. bulgaricus OLL1256 and $S$. thermophilus OLS3295. Splenocytes were incubated with concanavalin A for $72 \mathrm{~h}$. Values are means of 8 mice per group.

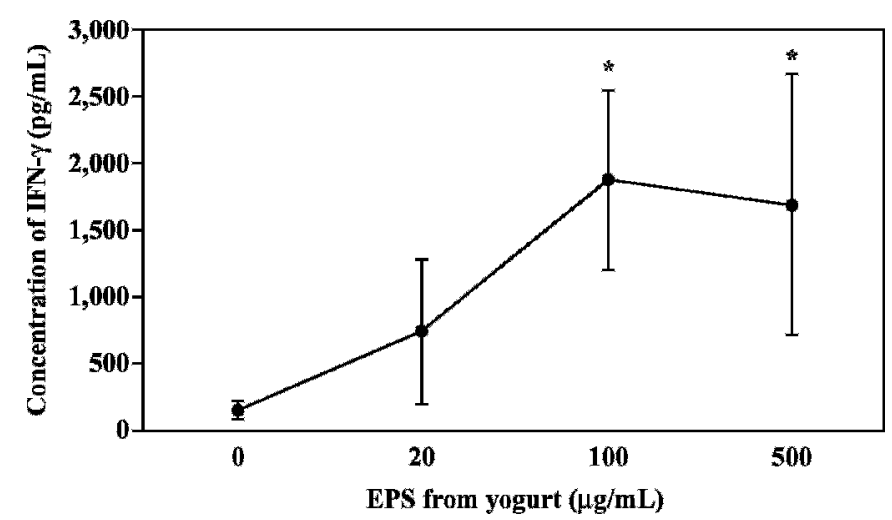

Figure 7. Effect of extracellular polysaccharides (EPS) purified from yogurt fermented with Lactobacillus bulgaricus OLL1073R-1 on IFN- $\gamma$ production from splenocytes of $\mathrm{C} 3 \mathrm{H} / \mathrm{HeJ}$ mice. Splenocytes were incubated with concanavalin A for $72 \mathrm{~h}$. Each bar represents the mean value and SD of 5 samples. An asterisk $(*)$ indicates $P<$ 0.05 compared with the control using the Dunnett's test. nuclear cells in healthy people with low levels of NK cell activity (Nagao et al., 2000; Hori et al., 2002). Natural killer cell activity is believed to play an important role in preventing the development of cancer, and a human study has shown that the high cytotoxic activity of peripheral blood lymphocytes is associated with reduced cancer risk (Imai et al., 2000).

In this respect, the presence of immunostimulative H-APS in yogurt fermented with $L$. bulgaricus OLL1073R-1 might augment human cellular immunity, protect against infection, and delay the growth of cancer.

\section{CONCLUSIONS}

This study shows that H-APS produced by L. bulgaricus OLL1073R-1 induces IFN- $\gamma$ production in mouse splenocytes in vitro and augments NK cell activity following oral administration. This is the first demonstration that the oral administration of EPS produced by L. bulgaricus can modulate the immune system. Moreover, splenocytes from mice administered yogurt fer- 
mented with $L$. bulgaricus OLL1073R-1 produced more IFN- $\gamma$ after stimulation with ConA, and augmented NK cell activity, although ConA-induced IL-4 production was suppressed. These findings suggest that milk products fermented with $L$. bulgaricus OLL1073R-1 could be considered functional foods.

\section{ACKNOWLEDGMENTS}

The authors thank Takashi Sasaki for critical reading of the manuscript.

\section{REFERENCES}

Bartlett, G. R. 1959. Phosphorous assay in column chromatography. J. Biol. Chem. 234:466-468.

Cross, M. L., L. M. Stevenson, and H. S. Gill. 2001. Anti-allergy properties of fermented foods: An important immunoregulatory mechanism of lactic acid bacteria? Int. Immunopharmacol. 1:891-901.

Dubois, M., K. A. Gilles, J. K. Hamilton, P. A. Rebrs, and F. Smith. 1956. Colorimetric method for determination of sugars and related substances. Anal. Chem. 28:350-356.

Ebina, T., N. Ogama, and K. Murata. 1995. Antitumor effects of Lactobacillus bulgaricus 878R. Biotherapy 9:65-70.

Gill, H. S. 1998. Stimulation of the immune system by lactic cultures. Int. Dairy J. 8:535-544.

Gill, H. S., K. J. Rutherfurd, J. Prasad, and P. K. Gopal. 2000. Enhancement of natural and acquired immunity by Lactobacillus rhamnosus (HN001), Lactobacillus acidophilus (HN017) and Bifidobacterium lactis (HN019). Br. J. Nutr. 83:167-176.

Gill, H. S., K. J. Rutherfurd, M. L. Cross, and P. K. Gopal. 2001. Enhancement of immunity in the elderly by dietary supplementation with the probiotics Bifidobacterium lactis HN019. Am. J. Clin. Nutr. 74:833-839.

Hori, T., J. Kiyoshima, K. Shida, and H. Yasui. 2002. Augmentation of cellular immunity and reduction of influenza virus titer in aged mice fed Lactobacillus casei strain Shirota. Clin. Diagn. Lab. Immunol. 9:105-108.

Imai, K., S. Matsuyama, S. Miyake, K. Suga, and K. Nakachi. 2000. Natural cytotoxic activity of peripheral-blood lymphocytes and cancer incidence: An 11-year follow-up study of a general population. Lancet 356:1795-1799.

Johann, S., G. Blümel, M. Lipp, and R. Förster. 1995. A versatile flow cytometry-based assay for the determination of short- and long-term natural killer cell activity. J. Immunol. Methods 185:209-216.
Kitazawa, H., T. Itoh, and T. Yamaguchi. 1991. Induction of macrophage cytotoxicity by slime products produced by encapsulated Lactococcus lactis ssp. cremoris. Anim. Sci. Technol. 62:861-866.

Kitazawa, H., T. Harata, J. Uemura, T. Saito, T. Kaneko, and T. Itoh. 1998. Phosphate group requirement for mitogenic activation of lymphocytes by an extracellular phosphopolysaccharide from Lactobacillus delbrueckii ssp. bulgaricus. Int. J. Food Microbiol. 40:169-175.

Kitazawa, H., T. Itoh, Y. Tomioka, M. Mizugaki, and T. Yamaguchi. 1996. Induction of IFN- $\gamma$ and IL- $1 \alpha$ production in macrophages stimulated with phosphopolysaccharide produced by Lactococcus lactis ssp. cremoris. Int. J. Food Microbiol. 31:99-106.

Kitazawa, H., T. Yamaguchi, M. Miura, T. Saito, and T. Itoh. 1993. B-cell mitogen produced slime-forming, encapsulated Lactococcus lactis ssp. cremoris isolated from ropy sour milk, Viili. J. Dairy Sci. 76:1514-1519.

Mossmann, T. R., and R. L. Coffman. 1989. Th1 and Th2 cells: Different patterns of lymphokine secretion lead to different functional properties. Annu. Rev. Immunol. 7:145-173.

Nagao, F., M. Nakayama, T. Muto, and K. Okumura. 2000. Effects of a fermented milk drink containing Lactobacillus casei strain Shirota on the immune system in healthy human subjects. Biosci. Biotechnol. Biochem. 64:2706-2708.

Nishimura-Uemura, J., H. Kitazawa, Y. Kawai, T. Itoh, M. Oda, and T. Saito. 2003. Functional alternation of murine macrophage stimulated with extracellular polysaccharides from Lactobacillus delbrueckii ssp. bulgaricus OLL1073R-1. Food Microbiol. 20:267-273.

Oda, M., H. Hasegawa, S. Komatsu, M. Kambe, and F. Tsuchiya. 1983. Anti-tumor polysaccharide from Lactobacillus sp. Agric. Biol. Chem. 47:1623-1625.

Ruas-Madiedo, P., J. Hugenholtz, and P. Zoon. 2002. An overview of the functionality of exopolysaccharides produced by lactic acid bacteria. Int. Dairy J. 12:163-171.

Sato, T., J. Nishimura-Uemura, T. Shimosato, Y. Kawai, H. Kitazawa, and T. Saito. 2004. Dextran from Leuconostoc mesenteroides augments immunostimulatory effects by the introduction of phosphate groups. J. Food Prot. 67:1719-1724.

Sheih, Y. H., B. L. Chang, L. H. Wang, C. K. Liao, and H. S. Gill. 2001. Systemic immunity enhancing effects in healthy subjects following dietary consumption of the lactic acid bacterium Lactobacillus rhamnosus HN001. J. Am. Coll. Nutr. 20:149-156.

Shu, Q., and H. S. Gill. 2001. A dietary probiotic (Bifidobacterium lactis HN019) reduces the severity of Escherichia coli O157:H7 infection in mice. Med. Microbiol. Immunol. 189:147-152.

Shu, Q., and H. S. Gill. 2002. Immune protection mediated by the probiotic Lactobacillus rhamnosus HN001 against Escherichia coli $\mathrm{O} 157: \mathrm{H} 7$ infection in mice. FEMS Immunol. Med. Microbiol. 34:59-64.

Uemura, J., T. Itoh, T. Kaneko, and K. Noda. 1998. Chemical characterization of exocellular polysaccharide from Lactobacillus delbrueckii subsp. bulgaricus OLL1073R-1. Milchwissenschaft $53: 443-446$. 